
\title{
3 Research S Quare \\ Risk Factors and Incidence for HAl in Elderly Patients Undergoing Neurosurgery in a Single Center
}

\section{Yunyun Liu}

Xuanwu Hospital Department of Neurosurgery

Tian Zhou

Xuanwu Hospital Department of Neurosurgery

Yuanyuan Ji

Xuanwu Hospital Department of Neurosurgery

Hongqi Zhang

Xuanwu Hospital Department of Neurosurgery

Jun Wang ( $\nabla$ wangjun@xwhosp.org )

Xuanwu Hospital

\section{Research}

Keywords: Health care-associated infection (HAl), Risk factors, Neurosurgery, Geriatrics, Intensive care, Nursing care

Posted Date: July 26th, 2021

DOI: https://doi.org/10.21203/rs.3.rs-725124/v1

License: (c) (1) This work is licensed under a Creative Commons Attribution 4.0 International License. Read Full License 


\section{Abstract}

Background: Health care-associated-infection (HAl) is an important issue in neurosurgery department. With the aging population, we are receiving an increasing number of elderly patients who have a higher risks of HAl.

AIM: We want to better understand risk factors of HAl and prevent HAl in elderly patients who accept neurosurgeries.

Methods: This was a case-control study. We took review of the medical records of patients aged 60 and older who underwent neurosurgical operations from 1 January to 31 December 2016 in a single centre. Patients with infection and intubation before admission were excluded. Risk factors and outcomes were analysed, including age, sex, activities of daily living (ADL) score, smoking history, emergency admission status, ICU stay, ventilator use, ventilation time, diabetes, coronary heart disease, immune system disease, consciousness at admission, albumin decrease, blood sugar, unplanned second operation, indwelling venous catheter, external ventricular drainage (EVD), discharge $A D L$, length of stay (LOS), and medical costs.

Results: A total of 1757 geriatric patients over 60 years underwent neurosurgical procedure were enrolled. Their age ranged from 60 to 93 years, with an average of $67.56 \pm 6.16$ years, including 1083 males(61.6\%)and 674 females(38.4\%).Among 1757 patients in 14703 hospital days, 95 cases of infection were diagnosed with HAls in 78 patients, The HAl rate was $4.4 \%(78 / 1757)$ and HAl case rate was 5.4\%(95/1757), incidence of HAl in neurosurgical geriatric patients was $6.5 \%$ o. Of these 95 infections, the most common types were pneumonia (65.3\%), followed by primary bloodstream infection (13.7\%), central nervous system infection (8.4\%), urinary tract infection (6.3\%), and wound infection $(6.3 \%)$. Multivariable logistic regression showed that the independent risk factors for HAl in elderly patients were ICU stay, mechanical ventilation, plasma albumin below $35 \mathrm{~g} / \mathrm{L}$, unplanned reoperation, and venous catheterization.

Conclusions: To prevent HAl, we should improve the ICU standards, decrease ventilation time, improve the nutrition supply, and dynamically evaluate the necessity of deep venous catheters and remove them as early as possible. Such measures could not only help reduce HAl and shorten hospital stays for elderly patients, but also decrease medical insurance cost for the government.

\section{Introduction}

Health care-associated-infection (HAl) is an important issue in hospital management. Previous studies have shown that cerebrospinal fluid (CSF) leakage, external ventricular drainage (EVD), infratentorial surgery, diabetes, the nature of the surgery, incision type, operation timing, and operation time are risk factors for intracranial infection after neurosurgery [1]. In addition, age, a history of chronic diseases, hospital stay, and invasive procedures are also considered risk factors [2]. However, few studies have specifically reported risk factors for elderly patients. The total number of older people (defined as 60 
years of age and over) worldwide is expected to increase from 605 million in 2000 to 1.2 billion by 2025 [3], and the morbidity of elderly infections is $18.57 \%$ [4]. HAI is an important issue that we focus on in the neurosurgical department, especially for elderly patients. This is important for the prevention and control of HAl after neurosurgery [5]. The aim of this study was to determine the rate and risk factors of HAl in elderly patients in the neurosurgery department, and the outcomes.

\section{Methods}

\section{Subjects}

Using the electronic database in hospital, consecutive patients who underwent neurosurgical operations between 1 January and 31 December 2016 at Xuanwu Hospital Capital Medical University were retrospectively identified. Hospital clinical data were extracted from 1757 patients. This study was approved by the Xuanwu Hospital Ethics Review Committee.

\section{Diagnostic criteria of infection}

Based on the clinical data, including symptoms, signs and laboratory examinations, the patients were divided into an infection group $(n=78)$ and a non-infection group $(n=1679)$. The diagnostic criteria were based on the Diagnostic Standards for Hospital Acquired Infections (Trial) issued by the Ministry of Health of the People's Republic of China on 3 January 2001 to define the criteria for the diagnosis of HAI [6]. Types of infection include pneumonia, primary bloodstream infection, urinary tract infection, central nervous system infection, wound infections, and the last two types were considered surgical site infections (SSIs).

\section{Risk factors and outcomes}

Univariate variable analyses of the risk factors, including age, sex, ADL, smoking history, emergency admission, ICU stay, ventilator usage, ventilation time, history of diabetes, history of coronary heart disease, history of immune system disease, consciousness at admission, low serum albumin level, high blood sugar, need for an unplanned second operation, and venous catheters, were conducted. The patient's short-term outcome was assessed by ADL at discharge, length of stay in hospital (LOS), and hospital expenses.

\section{Statistical analysis}

Epi Data 3.0 was used for data entry and system logic error detection. Statistical analysis was performed using SPSS 22.0. The count data are presented as frequencies (percentages), and the differences between groups were assessed using the $\chi 2$ test. Normally distributed continuous data are presented as the mean \pm standard deviation, and nonnormally distributed continuous data are presented as the median $\left(P_{25}, P_{75}\right)$. When the data were normally distributed and the between-group variance was equal, differences between groups were assessed using t-tests, while the rank sum test was used when the data showed a biased distribution. Univariate analysis was used to perform preliminary variable selection 
using an a level of 0.1 . On the other hand, logistic stepwise regression analysis was used to analyse independent risk factors for HAl in elderly patients who underwent neurosurgery. Differences with $\mathrm{P}<0.05$ were considered statistically significant.

\section{Results}

\section{Patients}

A total of 1757 geriatric patients over 60 years underwent at least one neurosurgical procedure were enrolled in a single center during this study period. Their ages ranged from 60 to 93 years old, average age was $67.56 \pm 6.16 .1083$ (61.6\%) were male, and 674 (38.4\%) were female.

\section{Prevalence and type distribution of health care associated infections}

A total of 78 patients with 95 infection cases were detected among 1757 patients in 14703 hospital days. The HAl rate was $4.4 \%(78 / 1757)$ and HAl case rate was $5.4 \%(95 / 1757)$, incidence of HAl was $6.5 \%$ o(95/14703) in neurosurgical geriatric patients. Consequently, $0.96 \%(17 / 1757)$ patients had at least two site infections, while there were 1679 non-infected cases in this study (Table 1, Fig. 1). Pneumonia (65.3\%), primary bloodstream infection (13.7\%), and central nervous system infection (8.4\%) were most common, followed by urinary tract infection $(6.3 \%)$ and wound infection $(6.3 \%)$.

Table 1

Types of 95 HAls in neurosurgical geriatric patients

\begin{tabular}{|lll|}
\hline Type of Infection & $\mathrm{n}$ & $\%$ \\
\hline Pneumonia & 62 & $65.3 \%$ \\
\hline Primary bloodstream infection & 13 & $13.7 \%$ \\
\hline Central nervous system infection & 8 & $8.4 \%$ \\
\hline Urinary tract infection & 6 & $6.3 \%$ \\
\hline Wound infection & 6 & $6.3 \%$ \\
\hline total & 95 & \\
\hline
\end{tabular}

\section{Univariate analysis of HAl}

Univariate analysis found that poor ADL score on admission, emergency admission, stay in the ICU, ventilation, mechanical ventilation over 48 hours, GCS less than 15, albumin below $35 \mathrm{~g} / \mathrm{L}$, high glucose, an unplanned second operation, venous catheterization and a long hospital stay were associated with HAl in neurosurgical patients over 60 years old (Table 2). 
Table 2

Risk factors for $\mathrm{HAl}$ in neurosurgical geriatric patients post operation

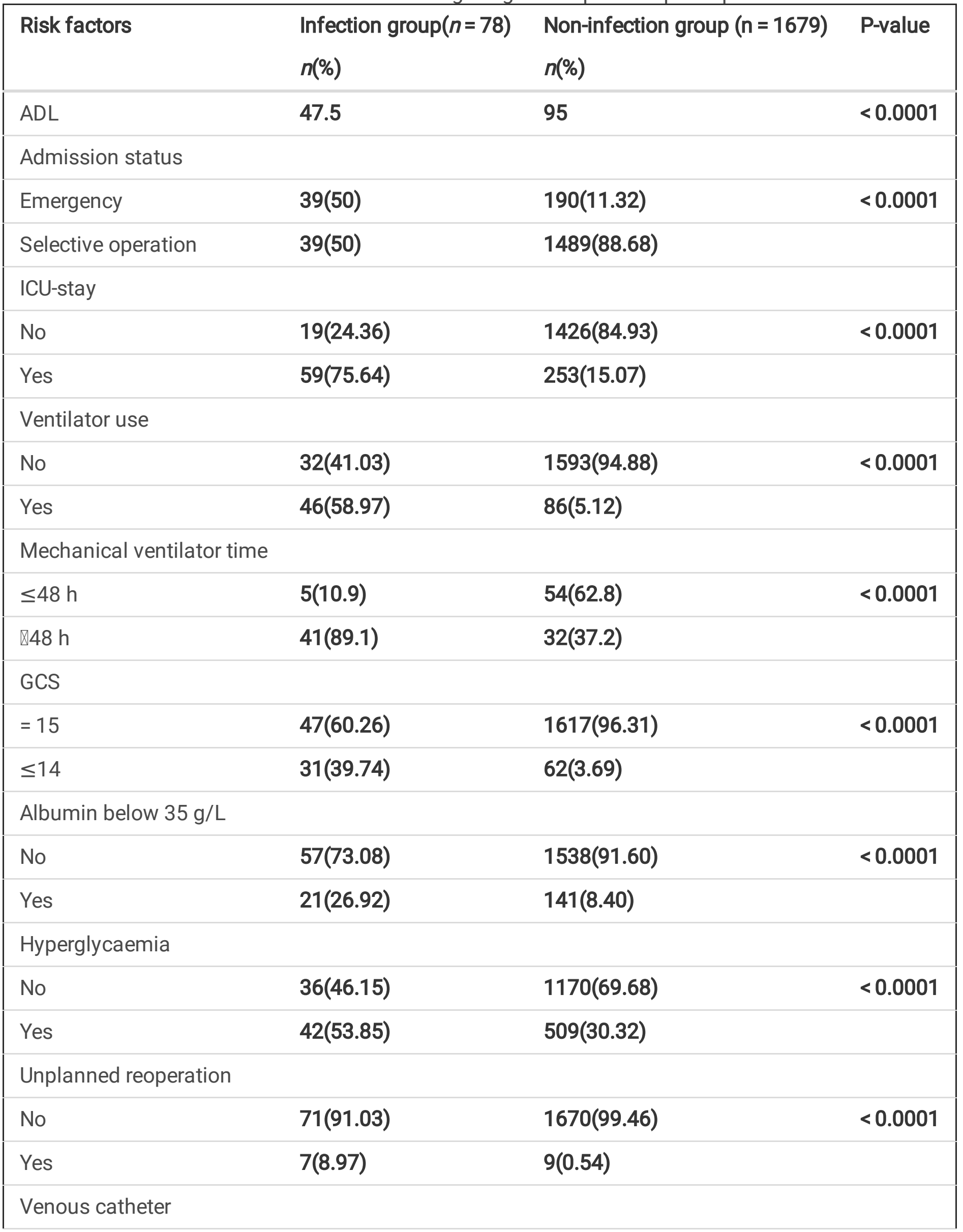




\begin{tabular}{|c|c|c|c|}
\hline Risk factors & $\begin{array}{l}\text { Infection group }(n=78) \\
n(\%)\end{array}$ & $\begin{array}{l}\text { Non-infection group }(n=1679) \\
n(\%)\end{array}$ & P-value \\
\hline No & $22(28.21)$ & $1523(90.71)$ & $<0.0001$ \\
\hline Yes & $56(71.79)$ & $156(9.29)$ & \\
\hline $\begin{array}{l}\text { Length of stay in hospital } \\
\left(\mathrm{P}_{25} \mathrm{P}_{75}\right)\end{array}$ & $18.5(13,26.25)$ & $6(4,9)$ & $<0.0001$ \\
\hline
\end{tabular}

\section{Multivariate analysis of HAl}

Multivariate analysis was performed for the variables for which $\mathrm{P}<0.1$ in the univariate analysis. Logistic regression showed that ICU stay $(\mathrm{OR}=2.878,95 \% \mathrm{Cl} 1.272-6.511)$, ventilator use $(\mathrm{OR}=2.975,95 \%, \mathrm{Cl}$ 1.433-6.176), plasma albumin below $35 \mathrm{~g} / \mathrm{L}(\mathrm{OR}=2.130,95 \% \mathrm{Cl} 1.131-4.011)$, reoperation out of plan $(\mathrm{OR}=4.210,95 \% \mathrm{Cl} 1.253-14.147)$, and venous catheterization ( $\mathrm{OR}=5.615,95 \% \mathrm{Cl} 2.691-11.719)$ were independent risk factors for HAl in patients over 60 years old who underwent neurosurgery. Table 3.

Table 3. Independent risk factors for HAl in neurosurgical geriatric patients post operation.

\begin{tabular}{|lll|}
\hline Risk factors & Adjusted OR*,95\% Cl & P \\
\hline ICU stay & $2.878(1.272,6.511)$ & 0.0112 \\
\hline Ventilator use & $2.975(1.433,6.176)$ & 0.0034 \\
\hline Albumin $₫ 35 \mathrm{~g} / \mathrm{L}$ & $2.130(1.131,4.011)$ & 0.0193 \\
\hline Unplanned reoperation & $4.210(1.253,14.147)$ & 0.0201 \\
\hline Venous catheterization & $5.615(2.691,11.719)$ & $<.0001$ \\
\hline OR = odds ratio, $\mathrm{Cl}=$ confidence interval. & \\
\hline *Adjusted for all other risk factors by inclusion in a multivariate logistic regression model. \\
\hline
\end{tabular}

\section{Outcomes}

The median ADL at discharge in HAl group were 20, while Non-HAl group were 90. Outcomes of the HAl group were obviously worse than the non-HAl group including, discharge ADL, Length of stay (LOS), and total expense in hospital. (Table 4, Fig. 2). HAl group's length of stay in hospital is 3.08 times longer than non-HAl group. Hospital cost in HAl group is $178802 \mathrm{RMB}, 3.3$ times more than non-HAl group, which is 54243RMB. 
Table 4

outcomes of HAl-group and Non-HAl group

\begin{tabular}{|llll|}
\hline & HAl group & Non-HAl group & $p$ \\
\hline ADL & $\mathbf{2 0}(0,70)$ & $90(70,100)$ & $<0.0001$ \\
LOS & $18.5(13,26)$ & $6(4,9)$ & $<0.0001$ \\
\hline Expense & $178802.61 \pm 120444.23$ & $54243.08 \pm 51345.73$ & $<0.0001$ \\
\hline
\end{tabular}

\section{Discussion}

The aim of this study was to identify risk factors for post-surgical infections in geriatric patients treated by neurosurgery. The analysis identified factors associated with postoperative neurosurgical infection, including ICU stay, ventilator usage, malnutrition (serum albumin under $35 \mathrm{~g} / \mathrm{L}$ ), unplanned reoperation, and venous catheterization.

\section{Infection rates}

HAls often occur in elderly patients after major surgery. Previous studies have shown that the postoperative infection rate in the neurosurgery department ranges from 3.52-17.97\% $[7,8]$. According to the present study, in the group of patients over 60 years old, the postoperative infection rate was $4.4 \%$ (78/1757), as while as case rate was $5.4 \%$, after neurosurgical procedures. Our study found that incidence rate of HAI in elderly patients after neurosurgery were $6.5 \%$. It means that in everyday, average $6.5 \%$ o elderly patients got infectious after neurosurgery.

\section{Infection types}

According to studies in Europe, the most common infection types are pneumonia, surgical-site infections, and gastrointestinal infections [7]. Other studies showed that pneumonia, bloodstream infection and central venous infection were the most common types [9]. The findings of this study were similar to the other studies for the types of infection, including pneumonia (65.3\%), primary bloodstream infection (13.7\%), central nervous system infections (8.4\%).[2, 10-12].

\section{Factors associated with perioperative period infection}

A study focusing on elderly patients in hospital showed that HAl occurred in $3.52 \%$ of patients, of whom $80 \%$ were in ICU, and the infection site was mainly the lower respiratory tract $(61.7 \%)[13,14]$. The authors of that study concluded that urinary catheterization and intubation are independent influencing factors. Another study found that the infection rate after neurosurgical procedures was $12.0 \%$, which occurred an average of 7 days after the operation [10]. This phenomenon indicated that the first week after operation is important for infection control. In this study, $0.91 \%$ of patients required at least one reoperation after surgery. The original disease also influences the situation. It has been proven that patients with brain 
tumours, hydrocephalus, or cerebral vascular disease are more likely to become infected [15]. Other factors, including age, operation duration, reoperation, and requiring a blood transfusion have been shown to be relevant. Another report revealed that the postoperative infection rate of elderly brain tumour patients was $7.39 \%$, which was associated with operative duration, administration of antibiotics, and chronic diseases [16]. In the present study, we found that there were no differences in age, sex, or a history of chronic disease between the infection group and the non-infection group. Other factors, including ADL, emergency admission, ICU stay, ventilation more than 48 hours, GCS $\leq 14$, serum album $\varangle 35 \mathrm{~g} / \mathrm{L}$, high level of blood glucose, reoperation, and venous catheterization, were associated with infection in elderly patients who underwent neurosurgery.

\section{SSI}

Surgical site infections, including incision infections, meningitis, and brain abscesses, often occur 5-7 days after the operation [5]. SSI will negatively influence the hospital days and expenses and even the prognosis of the patients. In this series, patients with HAl had an average of 18.5 days in hospital. EVD and a long operation duration are associated with SSI, and we noticed that some incision infections are directly caused by unfavourable suture techniques and postoperative management. Thus, the surgical team should be very careful regarding high-risk candidates and select suitable surgical methods to decrease the operation time and blood loss.

\section{Possible impact of HAl}

Worldwide, studies have shown that the average hospital stay of HAl patients is 30.4 days, compared with 10.6 days for non-infected patients. A meta-analysis showed that the morbidity of HAI was between $7 \%$ and $46 \%$, the average hospital stay was increased by 5 to 21 days, and the average extra expenses reached up to 13000 USD [17]. Another study reported that emergency admission patients had more hospital stays and a higher mortality than normal patients [18]. In this study showed that HAl group's length of stay in hospital was 3.08 times longer than non-HAl group. The medium Hospital expense in HAl group was 178802RMB ,3.3 times more than non-HAl group, which was 54243RMB.

\section{Limitations}

This was a retrospective study in a single centre. Because the aim of this study was to determine the modifiable factors associated with infection, we did not collect long-term follow-up data for all patients, so the long-term impact of HAI on patients and their prognosis is not yet clear and needs to be further studied.

\section{Conclusions}

We found a shorter ICU stay, shorter length of ventilator use, better nutrition supply for patients with albumin below $35 \mathrm{~g} / \mathrm{L}$, reducing unplanned reoperation, and careful evaluation of the necessity of venous catheters and removing them as early as possible could reduce the HAl rate in geriatric population. HAI prevention and control is a systemic task. We should recognize the high-risk factors and high-risk geriatric 
patients as early as possible. The prevention of hospital-acquired-infection can improve our clinical practice, enable patients to have better outcomes following neurosurgery and reduce the economic burden of medical insurance for the government.

\section{Abbreviations}

HAI

Health care-associated infection

ADL

Activities of daily living score

SSI

Surgical site infection

ICU

Intensive care unit

GCS

Glasgow coma scale

LOS

Length of stay

CSF

Cerebral spinal fluid

EVD

External ventricular drainage

OR

Operation room

$\mathrm{Cl}$

Confidence interval

\section{Declarations}

\section{Ethics approval and consent to participate}

This study was approved by the Xuanwu Hospital Ethics Review Committee (Clinical Research Council ([2019]142). For this type of study, formal consent is not required.

All procedures performed in studies involving human participants were in accordance with the ethical standards of the institutional and/or national research committee and with the 1964 Helsinki declaration and its later amendments or comparable ethical standards.

\section{Consent for publication}

Not applicable 


\section{Availability of data and materials}

The datasets obtained during this study are available from the corresponding author on reasonable request.

\section{Competing interests}

The authors declare that they have no conflict of interest.

\section{Funding}

Beijing Medical Research No. 2019-2

\section{Authors' contributions}

Jun Wang designed the study. Yunyun Liu designed the data collection tool. Yunyun Liu drafted and revised the manuscript. Tian Zhou monitored data collection. YuanYuan Ji mainly analyzed data. All authors read and approved the final manuscript.

\section{Acknowledgements}

Thanks is offered to my team leader and professor, Zhang Hongqi and my colleague doctor Chen Sichang.

\section{Authors' information}

1 Department of Neurosurgery, Xuanwu Hospital, Capital Medical University,

China International Neuroscience Institute (China-INI), 45 Changchun Street,

Beijing 100053, China.

\section{References}

1. Whitehouse KJ, Jeyaretna DS, Wright A, Whitfield PC. Neurosurgical care in the elderly: increasing demands necessitate future healthcare planning. World Neurosurg. 2016;87:446-54.

2. Patel S, Thompson D, Innocent S, Narbad V, Selway R, Barkas K. Risk factors for surgical site infections in neurosurgery. Ann R Coll Surg Engl. 2019;101:220-5.

3. Hopewell S, Copsey B, Nicolson P, Adedire B, Boniface G, Lamb S. Multifactorial interventions for preventing falls in older people living in the community: a systematic review and meta-analysis of 41 trials and almost 20000 participants. Br J Sports Med. 2020;54:1340-50.

4. Taylor ME, Oppenheim BA. Hospital-acquired infection in elderly patients. J Hosp Infect. 1998;38:245-60. 
5. Lopez Pereira P, Diaz-Agero Perez C, Lopez Fresnena N, Las Heras Mosteiro J, Palancar Cabrera A, Rincon Carlavilla $\mathrm{AL}$, et al. 'Epidemiology of surgical site infection in a neurosurgery department'. Br $\mathrm{J}$ Neurosurg. 2017;31:10-5.

6. Todd B. New CDC guideline for the prevention of surgical site infection. Am J Nurs. 2017;117:17.

7. Magill SS, Edwards JR, Bamberg W, Beldavs ZG, Dumyati G, Kainer MA, et al. Multistate pointprevalence survey of health care-associated infections. N Engl J Med. 2014;370:1198-208.

8. Elsamadicy AA, Sergesketter A, Sampson JH, Gottfried ON. Institutional review of mortality in 5434 consecutive neurosurgery patients: are we improving? Neurosurgery. 2018;83:1269-76.

9. Rubeli SL, D'Alonzo D, Mueller B, Bartlome N, Fankhauser H, Bucheli E, et al. Implementation of an infection prevention bundle is associated with reduced surgical site infections in cranial neurosurgery. Neurosurg Focus. 2019;47:E3.

10. Fang C, Zhu T, Zhang P, Xia L, Sun C. Risk factors of neurosurgical site infection after craniotomy: a systematic review and meta-analysis. Am J Infect Control. 2017;45:e123-34.

11. Sherrod BA, Arynchyna AA, Johnston JM, Rozzelle CA, Blount JP, Oakes WJ, et al. Risk factors for surgical site infection following nonshunt pediatric neurosurgery: a review of 9296 procedures from a national database and comparison with a single-center experience. J Neurosurg Pediatr. 2017;19:407-20.

12. Wang J, Ji Y, Jiang L, Zhao X, Guan S, Yang P, et al. Analysis of factors influencing hospital-acquired infection in postoperative patients with intracranial aneurysm. BMC Neurol. 2019;19:332.

13. Mallucci CL, Jenkinson MD, Conroy EJ, Hartley JC, Brown M, Dalton J, et al. Antibiotic or silver versus standard ventriculoperitoneal shunts (BASICS): a multicentre, single-blinded, randomised trial and economic evaluation. Lancet. 2019;394:1530-9.

14. Masnick M, Morgan DJ, Macek MD, Sorkin JD, Brown JP, Rheingans P, et al. Improving the understanding of publicly reported healthcare-associated infection (HAl) data. Infect Control Hosp Epidemiol. 2016;37:1349-54.

15. Matsuda S, Ikawa F, Ohba H, Yoshiyama M, Hidaka T, Kurisu K, et al. Questionnaire survey regarding prevention of surgical site infection after neurosurgery in Japan: focus on perioperative management and administration of surgical antibiotic prophylaxis. Neurol Med Chir (Tokyo). 2019;59:197-203.

16. Uzuka T, Takahashi H, Nakasu Y, Okuda T, Mitsuya K, Hayashi N, et al. Surgical site infection after malignant brain tumor resection: a multicenter study for induction of a basic care bundle. Neurol Med Chir (Tokyo). 2017;57:542-7.

17. Fan T, Shao L, Wang X, Ren P. Efficacy of copper-impregnated hospital linen in reducing healthcareassociated infections: a systematic review and meta-analysis. PLoS One. 2020;15:e0236184.

18. Bligh ER, Sinha P, Smith D, Al-Tamimi YZ. Thirty-day mortality and survival in elderly patients undergoing neurosurgery. World Neurosurg. 2020;133:e646-52.

\section{Figures}


A

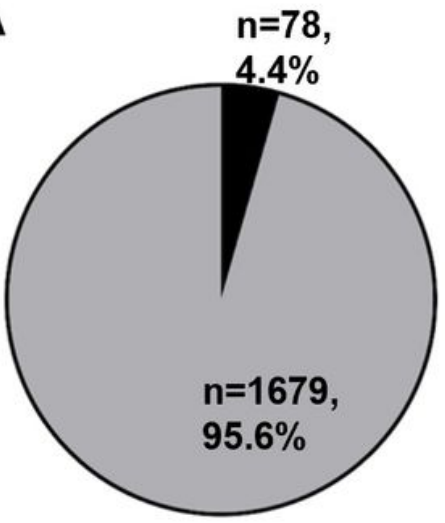

Total=1757
B

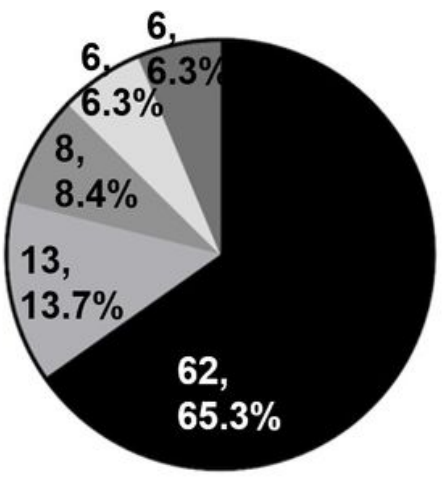

Total=95

Figure 1

Populational distribution of the enrolled patients. A. The rate of HAls in 1757 elderly patients. 78 patents $(4.4 \%)$ have endured a total of 95 HAls. B. Detailed description of the HAl. The largest population of the HAl was pneumonia.

A. ADL at Discharge

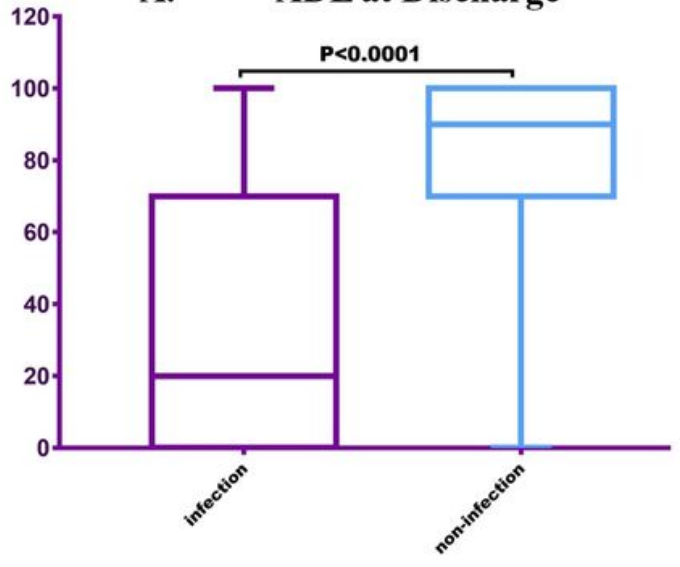

B. LOS

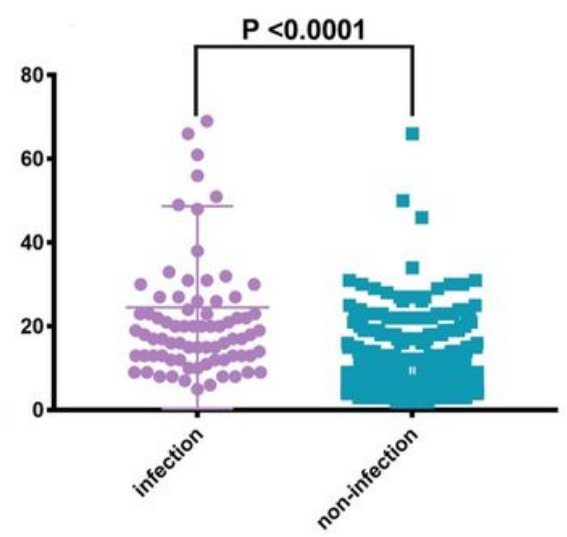

C. Hospital Costs

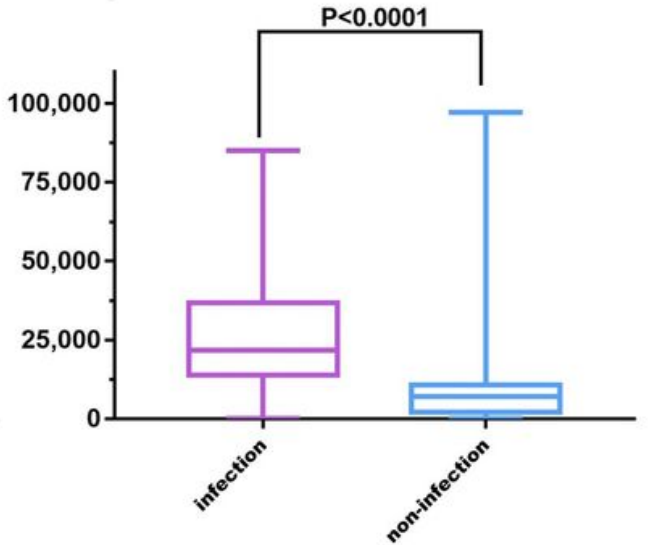

Figure 2

Box plot of the ADL at Discharge, LOS, and Hospital Costs between the infection group (left panel in each chart) and non-infection group (right panel in each chart). A. The ADL at discharge was obviously higher in non-infection group. B. The infections prolonged the length of stay dominantly for 3.08 times. C. The infection led to more costs in hospital. The costs for the infection and non-infection group were 178802.61 CNY (27231.64USD) and 54243.08 CNY (8261.22USD) on average, respectively. 